\title{
Results Obtained with the Laparoscopic Approach to the Bile Duct for the Treatment of Choledocholithiasis in 101 Cases
}

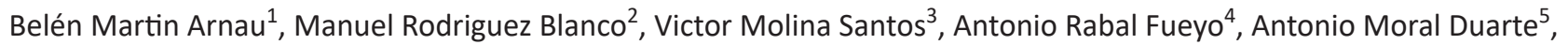 \\ Santiago Sánchez Cabús ${ }^{6}$
}

\begin{abstract}
Background:The optimal treatment for choledocholithiasis (CLT) is currently the subject of debate, as there is no clear evidence that a two-step (endoscopic plus surgical) approach is superior to a one-step surgical procedure.

Materials and methods: We analyzed the results obtained from 101 consecutive patients diagnosed with CLT using magnetic resonance cholangiopancreatography (MRCP) or computed tomography (CT) scan undergoing cholecystectomy and laparoscopic exploration of the bile duct, carried out at our center between 2006 and 2019. In this analysis, special emphasis was made on the permanent resolution of the CLT and the associated complications.

Results: The mean surgical time was $142 \pm 36.7$ minutes. In patients with a CLT diagnostic test more than 7 days previously, the presence of CLT was checked using intraoperative cholangiography (IOC), which was negative in $25 \%$ of patients, while in the rest, a primary exploration was performed using a choledochoscope via choledochotomy in $82.2 \%$ of patients and via the transcystic approach in two cases. A T-tube drain was inserted in $18.9 \%$ of patients. The conversion rate was $0.9 \%$, due to a technical difficulty in removing the CLT in one patient. The laparoscopic approach treated the CLT permanently in $97 / 101$ cases $(96 \%)$, while four patients (3.9\%) required postoperative endoscopic retrograde cholangiopancreatography (ERCP) due to residual cholelithiasis. A total of $15.8 \%$ of patients experienced a postoperative biliary fistula, which was resolved using conservative management in $86.7 \%$ of them, while two patients required surgical treatment and insertion of a percutaneous drain, respectively. The average postoperative stay duration was $6.5 \pm 7.3$ days. None of the patients showed signs of biliary stricture in the long-term postoperative follow-up.

Conclusion: In our experience, the laparoscopic approach for one-step elective treatment of CLT is a safe option, with a very small number of complications and satisfactory short- and long-term results. Furthermore, despite preoperative identification of CLT, it helped to avoid unnecessary exploration of the bile duct in $25 \%$ of patients.

Keywords: Cholangiopancreatography endoscopic retrograde, Choledocholithiasis, Laparoscopic cholecystectomy, Laparoscopic common bile duct exploration.
\end{abstract}

World Journal of Laparoscopic Surgery (2021): 10.5005/jp-journals-10033-1447

\section{INTRODUCTION}

Approximately, 9 to $16 \%$ of patients with cholelithiasis can experience concomitant choledocholithiasis (CLT). ${ }^{1,2}$ For many years, intraoperative cholangiography (IOC) was routinely carried out during open cholecystectomy with the aim of diagnosing inadvertent CLT, and in patients in whom it was diagnosed, an exploration of the main bile duct was carried out. ${ }^{3,4}$ Subsequently, with the implementation of laparoscopic surgery to treat cholelithiasis and thanks to the advances in preoperative imaging techniques and the experience gathered in laparoscopy, the approach to CLT treatment has evolved. Nowadays, attempts are made to diagnose CLT preoperatively, and, in general, endoscopic retrograde cholangiopancreatography (ERCP) is carried out, followed by laparoscopic cholecystectomy (LC) (a two-step procedure), which has emerged as the standard treatment. ${ }^{5}$

However, the use of ERCP has been associated with morbidity and mortality rates of up to 15 and $1 \%$, respectively, and it has a CLT recurrence rate of 10 to $15 \%,{ }^{5}$ as well as an increase in the cost (whether direct or indirect) associated with a two-step procedure. In contrast, the surgical treatment of CLT using a laparoscopic approach is currently feasible thanks to the increase in the experience and availability of choledochoscopes adapted for the laparoscopic approach, allowing for the exploration of the bile duct laparoscopic common bile duct exploration (LCBDE) and cholecystectomy to be carried out simultaneously. ${ }^{6}$ Despite its

\begin{abstract}
${ }^{1-6}$ Department of Digestive Surgery, Hospital Sant Pau, Barcelona, Catalonia, Spain

Corresponding Author: Belén Martin Arnau, Department of Digestive Surgery, Hospital Sant Pau, Barcelona, Catalonia, Spain, e-mail:amartinar@santpau.cat

How to cite this article: Arnau BM, Blanco MR, Santos VM, et al. Results Obtained with the Laparoscopic Approach to the Bile Duct for the Treatment of Choledocholithiasis in 101 Cases. World J Lap Surg 2021;14(2):119-125.
\end{abstract}

Source of support: Nil

Conflict of interest: None

technical difficulty, this approach can have benefits compared to the conventional ERCP and LC procedures, reducing the duration of the hospital stay and the total cost, and even has a higher rate of permanent treatment for CLT.

In this study, we describe the results associated with the use of the one-step laparoscopic approach for treating CLT and cholelithiasis.

\section{Materials and Methods}

Between September 2006 and March 2019, we carried out 101 consecutive cholecystectomy procedures with the laparoscopic 
exploration of the bile duct in patients with CLT diagnosed via an imaging study.

The data from these patients were collected prospectively in a database and were analyzed retrospectively. The variables analyzed were as follows: Preoperative data: Age, sex, liver function tests, and diagnostic imaging studies [ultrasound, computed tomography (CT) scan, and magnetic resonance cholangiopancreatography (MRCP)]. The intraoperative data included the following: Surgical time, transcystic or transcholedochal approach, the performance of IOC, use of sealants, and the need for conversion. In the postoperative period, we recorded the duration of the hospital stay, postoperative complications (pancreatitis, bile leakage, cholangitis, and bleeding), and follow-up data on the recurrence of stones, as well as the need for subhepatic or biliary drainage, the time to removal of the drain and the associated complications.

\section{Patient Selection}

Patients were included who had clinical and laboratory signs that were suggestive of CLT (pain of probable biliary origin and jaundice) that was confirmed with an imaging study, and those with signs of associated cholecystitis were excluded. Radiological diagnosis of CLT was carried out via abdominal ultrasound in 15 patients (14.8\%), CT scan in 6 patients (5.9\%), and MRCP in 80 patients (79.2\%).

Informed consent was obtained from all patients after they had been given information about their disease, the up-to-date treatment options, and the possibility of conversion to conventional open surgery.

\section{Surgical Technique}

All patients received antibiotic and antithrombotic prophylaxis in line with the center's policy. The supine position was used, allowing the fluoroscopic C-arm to be inserted to carry out the IOC.

As standard, an IOC was carried out in all patients, except those with CLT demonstrated by an imaging study (abdominal ultrasound, CT scan, or MRCP) in the 7 days prior to the surgical intervention. If an image suggestive of CLT was observed in the IOC (filling defect or no passage of contrast to the duodenum), a surgical exploration of the bile duct was carried out.

The procedure was carried out using a LC technique with the use of four trocars (American technique), as previously described. ${ }^{7}$ After completely dissecting the triangle of the Calot, a small incision was made in the cystic duct following proximal clipping of the duct to prevent the stones from sliding into the common hepatic duct. A small-diameter catheter (4.5 Fr) was inserted through the cystic duct to carry out the IOC and to detect any images suggestive of CLT or any anatomical variations, if applicable. If any images minimally suggestive of CLT were observed, surgical exploration with a choledochoscope was indicated.

\section{Transcystic Approach}

This approach was used in cases with a large cystic duct, which allowed the material to be inserted for the removal or a single CLT of a smaller size than the cystic duct.

After dilating the cystic duct with the laparoscopic dissector, the stones were removed from the main bile duct using a pressure infusion of saline solution and subsequently, in all cases, with the assistance of a Dormia basket ${ }^{8}$ or a balloon catheter (Fogarty $\left.{ }^{\circledR}\right){ }^{9}$ After the CLT expulsion maneuvers, a flexible choledochoscope was used ${ }^{10}$ to check that there was no residual CLT. The LC was then completed in the usual way.
In these patients, given that the main bile duct remained intact, an abdominal drain was not routinely placed.

\section{Choledochotomy Approach}

This approach was carried out in cases in which the requirements for a transcystic approach were not met (multiple or large-size CLT, small-diameter cystic duct) or if the transcystic approach was unsuccessful.

Exploration of the bile duct was carried out using a longitudinal choledochotomy on the anterior surface measuring around $2 \mathrm{~cm}$ in length. The techniques used to remove the stones were lavage with the saline solution under pressure to facilitate the removal of the small stones and using the Dormia basket and/or balloon catheter to move the stones toward the abdominal cavity via the choledochotomy or else toward the duodenum. In all cases, a choledochoscope was subsequently used in the distal and proximal direction to rule out the presence of the residual CLT.

After the removal of the CLT, the choledochotomy incision was closed over a Kehr drain, which was passed progressively, and in accordance with experience, to the primary closure with individual $4 / 0$ braided absorbable sutures, except in cases of acute cholangitis.

In these patients, a Jackson Pratt $^{\oplus}$ no. 13 low-pressure closedsuction abdominal drain was inserted. ${ }^{10}$

\section{Complication Assessment}

We used the ClavienDindo (CD) classification to stratify the severity. Bile leakage was defined as persistent bile drainage of over $50 \mathrm{~mL} /$ day for more than 3 days. ${ }^{7}$

\section{Statistics}

The continuous variables were compared using the Student's $t$-test or the MannWhitney $U$ test, as appropriate. The Chi-squared test was used to compare categorical variables. $p<0.05$ was considered to be statistically significant. Unless specifically stated otherwise, the data are shown as a mean \pm standard deviation.

The statistical analysis was carried out using the commercially available STATA software for Windows version 14 .

\section{Results}

Between September 2006 and March 2019, we carried out 101 LCBDE procedures due to lithiasis at our center. Table 1 shows the demographic characteristics.

Seventy-two patients (71.2\%) had diagnostic radiology studies for CLT carried out more than 7 days before the intervention. These patients underwent an IOC, the result of which showed no CLT in 14/72 patients (19.4\%) and a clear presence of CLT in 54/72 patients (75\%). In the remaining $4 / 72$ cases $(5.5 \%)$, normal bile-duct morphology

Table 1: Demographic characteristics of the study population subjected to $\mathrm{LCBDE}$

\begin{tabular}{lll}
\hline & $(n=101)$ & $\%$ \\
\hline Sex $(+/ \hat{)})$ & $55 / 46$ & $54.4 / 45.6$ \\
Middle ages & $69.3 \pm 16.8$ & \\
Abdominal surgical history & 24 & 23.5 \\
Gynecological & 11 & 10.9 \\
Appendectomy & 6 & 5.9 \\
Billroth gastrectomy II & 3 & 2.9 \\
Eventroplasty & 2 & 1.9 \\
Left hemicolectomy & 2 & 1.9 \\
\hline
\end{tabular}


was observed up to the outlet, but with no signs of the passage of contrast to the duodenum. In these cases, pressure infusion of saline solution was carried out, with subsequent insertion of a balloon catheter through the transcystic route. In three cases (4.16\%), no stone release was observed and the subsequent IOC was performed normally. In one patient (1.3\%), a transcystic choledochoscopy was able to be carried out, which ruled out the presence of the residual stones (Flowchart 1). From the laboratory perspective, the patients with and without CLT (definitively diagnosed during the intervention) did not have significantly different preoperative levels of aspartate aminotransferase ( $90.6 \pm 93.9$ vs $107.0 \pm 154.9, p=n s)$, alanine transaminase $(131.7 \pm 157.8$ vs $163.8 \pm 156.9, p=n s)$, total bilirubin $(39.0 \pm 49.5$ vs $23.5 \pm 21.1, p=n s)$, gamma-glutamyl transferase $(819.2 \pm 848.4$ vs $541.7 \pm 431.8, p=\mathrm{ns})$, and alkaline phosphatase ( $373.0 \pm 390.2$ vs $275.5 \pm 195.9, p=n s)$. It should be highlighted that these laboratory results were only available for 66 patients in the 3 weeks prior to the surgical intervention.

In the patients with confirmed CLT, the exploration of the bile duct was realized using the transcystic approach in two patients (2.5\%) and the transcholedochal approach in 97.5\% (81/83). The CLT was satisfactorily resolved in all patients undergoing the transcystic approach, while four patients (3.9\%) who underwent the transcholedochal approach had residual CLT. The primary closure of the choledochotomy was carried out in $80.2 \%$ (65/81), with choledochorraphy over a Kehr drain in $19.8 \%$ (16/81) of patients. The patients with a Kehr drain maintained this in situ for $26.3 \pm 23.7$ days before it was removed.

All procedures were carried out using a laparoscopy except one case $(0.9 \%)$ in which conversion to open surgery was performed due to difficulties in removing the CLT. There were no statistically significant differences in the conversion rate according to the approach (0.9 vs $0 \%, p=0.98)$.

The mean surgical time was $142 \pm 36.7$ minutes, with the transcystic route being $170 \pm 14.1$ minutes and the transcholedochal route being $141 \pm 36.9$ minutes $(p=0.28)$. The mean postoperative stay duration was $6.5 \pm 7.3$ days, being longer for the group undergoing the transcholedochal approach (6.7 \pm 7.6 days) than for the transcystic approach ( $2 \pm 0.0$ days) although without statistically significant differences $(p=0.38)$.

Sixteen patients $(18.5 \%)$ experienced a biliary fistula that persisted for $19 \pm 17.3$ days (International Study Group of Liver Surgery classification of the severity of bile leakage). ${ }^{31}$ Two of these patients had a Kehr drain in situ, and 14 belonged to the primary-closure group. Conservative management was carried out in 14 patients with the drain remaining in situ until resolved. Two patients required treatment to resolve the biliary fistula; one required reintervention for surgical drainage of the biloma, and the other required insertion of a percutaneous drain. Neither of these two cases had a T-tube in situ. No statistically significant differences were found between the presence of a biliary fistula in patients with and patients without a Kehr drain (21.5 vs $13.3 \%, p=1)$ (Table 2). The medical complications are summarized in Table 3. A total of six patients experienced medical complications in the form of pneumonia, urinary tract infection, and postoperative adynamic ileus, which progressed well with medical treatment.

The overall mortality for the series was $1.9 \%(2 / 101)$, secondary to bleeding complications. Overall, three patients $(2.9 \%)$ experienced postoperative bleeding, with two cases requiring reintervention: One patient experienced liver cirrhosis that had not been previously diagnosed, presenting with decompensation and subsequent multiple organ failure following bleeding of the cystic artery, eventually resulting in death; another patient experienced a hypovolemic shock secondary to a pseudoaneurysm of the gastroduodenal artery, eventually resulting in death despite emergency reintervention; the third case of bleeding corresponded to a hematoma in the surgical bed, which was treated conservatively (Tables 3 and 4).

The postoperative stay duration was $6.5 \pm 7.3$ days. None of the patients showed clinical, laboratory, or radiological signs of biliary stricture in the long-term postoperative follow-up.

Flowchart 1: Outline of the results

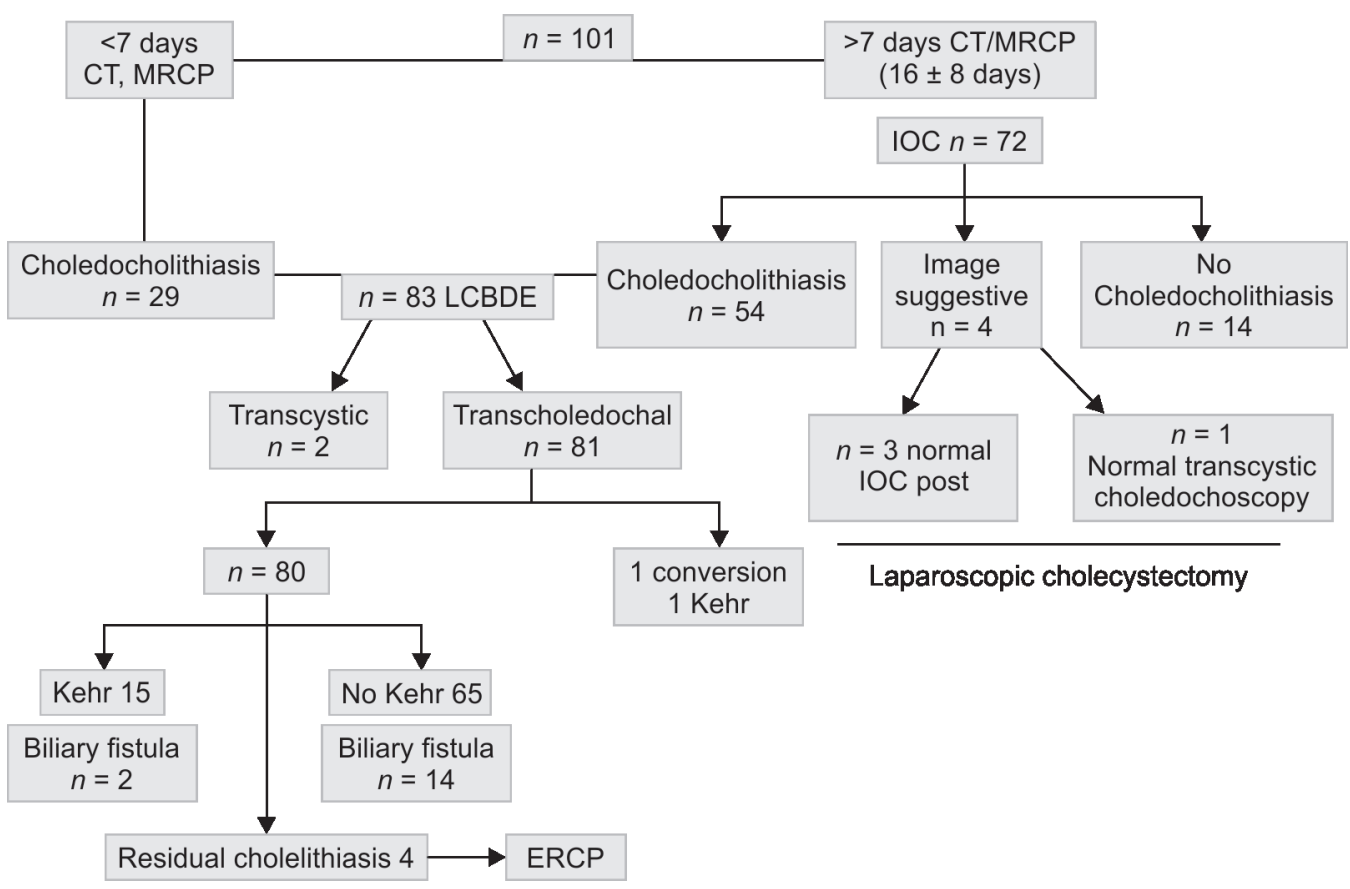


Overall, the LCBDE approach achieved full resolution of the CLT in $96.4 \%$ of patients (80/83). Three patients (3.6\%) required removal of residual CLT via ERCP, two of which were detected via transKehr cholangiography and two as a result of persistent cholestasis confirmed via MRCP due to not having a Kehr drain in situ.

\section{Discussion}

Cholelithiasis is a highly prevalent condition in our environment. It is estimated to affect $10 \%$ of the population in Spain, and a considerable percentage of these cases $(9-16 \%)$ can be associated with concomitant CLT. ${ }^{11,12}$ This represents a considerable problem that is in need of a suitable strategy to resolve it. For years, the European Association for Endoscopic Surgery has recommended that these patients be treated even when asymptomatic. ${ }^{13}$ Treatment options include a one-step procedure [cholecystectomy with exploration of the bile duct, whether via an open or laparoscopic approach (LCBDE)] or a two-step procedure with ERCP before or after LC. While ERCP has emerged as the gold standard for treating CLT, we must not forget that this is a technique that is associated with potentially severe complications, such as acute pancreatitis (1.8-8.6\%), cholangitis (1-5\%), bleeding (0.76-2.3\%), and bowel perforation (0.3-1.2\%), following endoscopic sphincterotomy (ES). ${ }^{14}$

Table 2: Biliary fistula

\begin{tabular}{lccc}
\hline \multicolumn{3}{c}{ Fistula } \\
\hline Kehr drain & Yes & Not & Total \\
Yes & $1.9 \%(2)$ & $13.8 \%(14)$ & 16 \\
Not & $13.8 \%(14)$ & $70.2 \%(71)$ & 85 \\
Total & 16 & 85 & 101 \\
\hline
\end{tabular}

Two-sided Fisher's exact $=1$

Table 3: Postoperative complications

\begin{tabular}{lcc}
\hline Complications & $N$ & $\%$ \\
\hline Biliary fistula & 16 & 15.8 \\
Residual choledocholithiasis & 4 & 3.9 \\
Bleeding & 3 & 2.9 \\
Residual collection & 3 & 2.9 \\
Caledonian stenosis & 0 & 0 \\
Paralytic ileus & 1 & 0.9 \\
Pneumonia & 2 & 1.9 \\
Urinary infection & 3 & 2.9 \\
\hline
\end{tabular}

Table 4: Postoperative complication grouped according to $C D$ classification

\begin{tabular}{lrl}
\hline Postoperative complication of CD & $N$ & $\%$ \\
\hline Minor & 21 & 20.8 \\
I & 17 & 16.8 \\
II & 4 & 3.9 \\
Major & 8 & 7.9 \\
IIIa & 5 & 4.9 \\
IIIb & 1 & 0.9 \\
IV & 0 & 0 \\
V & 2 & 1.9 \\
\hline
\end{tabular}

The best approach for treating CLT and cholelithiasis remains the subject of discussion. A Cochrane review concluded that there were no significant differences in morbidity, mortality, and failure rate between the LCBDE approach and the two-step endoscopic approach. However, individual trials have suggested that the onestep procedure gives a lower morbidity result, a shorter duration of hospital stay, and is more cost-effective than the two-step approach. ${ }^{15-17}$

From a theoretical perspective, the LCBDE approach would allow to prevent the inconveniences of two-step treatment of CLT and also the inconveniences of the open exploration. ${ }^{18,19}$ However, laparoscopic exploration of the bile duct has not been universally adopted, even to date, more than 30 years after the LC was introduced. The reasons for this delay are the good results and convenience associated with endoscopic treatment, as well as the technical difficulties related to the laparoscopic exploration of the bile duct, as it requires an instrument that is not always available, as well as operating room availability for the procedure to be performed, as it is technically demanding and requires a high level of experience. $^{20,21}$

In this study, we present the experience accumulated at our center in terms of the CEBLAS approach executed in the context of elective treatment of CLT in a series of more than 100 patients carried out over 13 years. We have confirmed that it is feasible and reproducible and is associated with a low number of failures and complications, with a CLT resolution success rate of $96.4 \%(80 / 83)$ in patients diagnosed intraoperatively with CLT with a resolution rate of $97 \%(98 / 101)$ for the whole series. These results are comparable to those reported in the literature regarding exploration with ERCP and open exploration of the main bile duct, with lower morbidity and mortality rates than these approaches. ${ }^{22-24}$

For the whole series, the presence of CLT was confirmed in $82.2 \%(83 / 101)$ either via IOC or via a preoperative imaging study (MRI or CT scan). Seventy-two patients underwent surgery more than 7 days after the diagnostic test, and, as such, the first intraoperative task was to confirm the presence of CLT via IOC. Surprisingly, 14 patients had a normal IOC, and a further 4 patients had an IOC that was unclear. Finally, these 18 patients ( $25 \%$ of the patients with a diagnostic study for CLT more than 7 days previously) did not have CLT, and surgical exploration of the bile duct was, therefore, not necessary. In comparative terms, some authors, such as Del Pozo et al., have reported up to $12.5 \%$ "blank ERCP." 25

The ideal approach for the surgical exploration of the bile duct is the transcystic approach, which is technically easier and has the advantage of keeping the main bile duct intact. However, its use has limitations and indications that are mainly determined by the diameter of the cystic duct, the number and size of the stones, and the potential presence of an endoprosthesis in the main bile duct, as well as the inability to carry out a proximal exploration of the common hepatic duct with the choledochoscope through the cystic duct. ${ }^{21-23}$ In our series, this approach could only be used in two patients (1.9\%) with a $100 \%$ success rate. For the rest of the patients, the transcholedochal approach was used, even though this is a technically demanding approach that requires the advanced laparoscopic experience. ${ }^{26,27}$ This approach was used in $97.5 \%$ of patients (81/83). The flexible choledochoscope is a highly useful tool in the exploration of the main bile duct, both in direct visualization of the intraluminal calculi and in the removal with the assistance of a Dormia basket or Fogarty vascular catheter. ${ }^{18,28-30}$ 
We used the choledochoscope in all cases with diagnostic imaging studies more than 7 days previously or in cases with CLT diagnostic IOC to confirm its removal.

The postoperative stay following LC is generally short (from 1 to 3 days) and increases significantly if the procedure includes laparoscopic exploration of the bile duct (from 1 to 7 days). 22,30-32 In our study, the mean postoperative stay duration for all patients was $6.5 \pm 7.3$ days. As a result of the wide disparity in the number of patients in each group, we did not find any statistically significant differences between the transcystic approach and the choledochotomy group $(6.7 \pm 7.6$ vs 2 days, $p=0.38)$. The transcystic approach is a technique that has very good results, with resolution in $90 \%$ of cases if a flexible choledochoscope is available and in $60 \%$ when radiology-guided, with a short, rapid postoperative recovery period. Furthermore, it keeps both the main bile duct and the sphincter of Oddi intact, which makes it particularly interesting; whenever possible, this should be the route of choice. ${ }^{33}$

The overall complication rate in our series was $28.7 \%$ (29 patients). Most of these complications were of surgical origin, particularly postoperative biliary fistula (16 patients, 15.8\%) and residual CLT (4 patients, 3.9\%). In terms of biliary fistula, most cases did not require specific treatment, given that these were low-flow fistulas that did not affect the patients' general clinical condition. No relationship was found between the presence of a postoperative biliary fistula and the insertion of a Kehr drain (1.9 vs 13.8\%, $p=n s)$. This has already been reported in other studies, such as the recent meta-analysis by Poddal et al., in which no differences were found in terms of a biliary fistula between those with a Kehr drain in situ and those without, and they report $3.9 \%$ of cases with biliary peritonitis following Kehr removal, with no significance compared to the primary-closure group. ${ }^{34}$

In our study, the choledochotomy was sutured over the Kehr drain in $18.9 \%$ of patients. Closure over the Kehr drain provides biliary decompression, as well as drainage in cases of cholangitis, and allows us to obtain images of the biliary system after the operation, providing an access through which residual stones can be removed. It also has its drawbacks, in that it could open up a route for bacteremia, accidental premature dislocation, and obstruction, and it could be associated with bile leakage and peritonitis after its removal. Given this, it was removed in our study after a mean period of 3 weeks (range: 10-105 days).

However, the presence of residual CLT, while uncommon (four cases, 3.9\%), always required another invasive procedure to be performed, generally an endoscopic procedure, for it to be resolved. Interestingly, in most cases (3/4), an exploration of the bile duct had been carried out via direct vision with a flexible choledochoscope, which is considered to be the best diagnostic technique for CLT. The reasons behind what happened could be explained by the presence of small-size calculi or their intrahepatic migration; it is worth noting that, of these four patients, two underwent confirmation with IOC and the other two with choledochoscopy. We consider that the surgeon's experience in carrying out the procedure and maneuvering the choledochoscope could have had an effect on there not being any residual CLT observed intraoperatively, as the four cases recorded corresponded to patients from the start of the series. According to the literature, the rate of post-ERCP residual CLT is higher, reaching up to $6 \%$ in some series, while this is $1-2 \%$ following cholecystectomy. ${ }^{35}$
A randomized trial published by Bansal et al. shows how the rate of complications between the LCBDE approach and the ERCP were comparable, with most of the LCBDE group having a CD classification of I and the ERCP group having sphincterotomy distributed among the rest of the CD classifications. ${ }^{36}$ It should be highlighted that, of the rest of the complications, postoperative bleeding was a severe complication in our series, which required reintervention in two patients. In terms of the modified CD classification, ${ }^{7}$ most of the complications were minor (20.8\%), with $7.9 \%$ of major complications. Of these, it is worth highlighting a mortality rate of $1.9 \%$ (two cases), both of which were secondary to bleeding. One of the cases was a patient with previously unknown cirrhosis, who presented with decompensation and subsequent multiple organ failure following bleeding, meaning this was a high-risk patient. The other patient experienced hypovolemic shock secondary to pseudoaneurysm of the gastroduodenal artery, with emergency reintervention to control the bleeding, which was a severe complication leading to massive bleeding and eventually resulting in death. Three patients experienced a postoperative residual intra-abdominal collection that progressed well with antibiotic treatment. In most studies, the mortality rate of the laparoscopic exploration of the main bile duct is 0 to $1 \%$ in the hands of experienced biliary surgeons. This rate is similar to the incidence found in the open exploration of the bile duct, ${ }^{37-41}$ as well as for the endoscopic approach $(0-1.5 \%){ }^{42-44}$

Some authors describe postoperative bleeding as a very rare complication but one which is responsible in most cases for early reintervention. It usually occurs after a difficult cholecystectomy or in patients with coagulation abnormalities, with patients with cirrhosis being those at the highest risk. Generally speaking, this type of intervention restricts surgeons to use local hemostatic agents and to insert a suction drain in the subhepatic position. It is important to highlight the serious nature of a reintervention, as $10 \%$ of patients undergoing further surgery will have severe complications. $^{45-47}$

After long-term follow-up of over 24 months, we did not observe any cases of bile duct stricture or cholangitis, in line with other studies. We, therefore, consider that another benefits of this approach should be highlighted, as carrying out ERCP with ES causes increasing repeat cholangitis, as we have previously mentioned.

Our study has some limitations, in that it is a retrospective study with a relatively small sample size. This study represents our experience to date in laparoscopic exploration of the bile duct.

\section{Conclusion}

In our experience, the laparoscopic approach for one-step elective treatment of CLT and cholelithiasis is a safe option, with a very small number of complications and satisfactory short- and longterms results, making use of the benefits of the minimally invasive approach and avoiding the inconveniences of ERCP, as well as the open approach. Furthermore, despite preoperative identification of CLT, it allowed us to avoid an unnecessary exploration of the bile duct in $25 \%$ of patients.

\section{References}

1. Nahrwold D. The biliary system. In: Sabiston X, editor. Textbook of surgery. Philadelphia: WE Saunders; 1986. 
2. WayLW, AdmirandWJ, Dunphy JE.Management of choledocholithiasis. Ann Surg 1972;176(3):347-359. DOI: 10.1097/00000658-19720900000011.

3. Petelin JB. Laparoscopic common bile duct exploration: lessons learned from $>12$ years experience. Surg Endosc 2003;17(11):17051715. DOI: 10.1007/s00464-002-8917-4.

4. Escat J, Fourtanier G, Maigne C, et al. Choledochoscopy in common bile duct surgery for choledocholithiasis: a must. Am Surg 1985;51(3):166-167. PMID: 3977190.

5. Fink AS. Current dilemmas in management of common duct stones. Surg Endosc 1993;7(4):285-291. DOI: 10.1007/BF00725941.

6. Newman KD, Powell DM, Holcomb III GW. The management of choledocholithiasis in children in the era of laparoscopic cholecystectomy. J Pediatr Surg 1997;32(7):1116-1119. DOI: 10.1016/ s0022-3468(97)90411-5.

7. Clavien PA, Barkun J, de Oliveira ML, et al. The Clavien-Dindo classification of surgical complications: five-year experience. Ann Surg 2009;250(2):187-196. DOI: 10.1097/SLA.0b013e3181b13ca2.

8. Traverso LW, Roush TS, Koo K. CBD stones-outcomes and costs. Laparoscopic transcystic techniques other than choledochoscopy. Surg Endosc 1995;9(11):1242-1244. PMID: 8553247.

9. Liberman MA, Phillips EH, Carroll BJ, et al. Cost-effective management of complicated choledocholithiasis: laparoscopic transcystic duct exploration or endoscopic sphincterotomy. J Am Coll Surg 1996;182(6):488-494. PMID: 8646348.

10. Phillips EH. Laparoscopic transcystic duct common bile duct exploration—outcome and costs. Surg Endosc 1995;9(11):1240-1242. PMID: 8553246.

11. Topal B, Aerts R, Penninckx F. Laparoscopic common bile duct stone clearance with flexible choledochoscopy. Surg Endosc 2007;21(12):2317-2321. DOI: 10.1007/s00464-007-9577-1.

12. Hanif $F$, Ahmed $Z$, Samie MA, et al. Laparoscopic transcystic bile duct exploration: the treatment of first choice for common bile duct stones. Surg Endosc 2010;24(7):1552-1556. DOI: 10.1007/s00464-009-0809-4.

13. Traverso LW. A cost-effective approach to the treatment of common bile duct stones with surgical versus endoscopic techniques. WB Saunders; 1996. p. 154-160.

14. Perissat J, Huibregtse K, Keane FV, et al. Management of bile duct stones in the era of laparoscopic cholecystectomy. Br J Surg 1994;81(6):799-810. DOI: 10.1002/bjs.1800810606.

15. Petelin J. Laparoscopic approach to common duct pathology. Surg Laparosc Endosc 1991;1(1):33-41. PMID: 1669374.

16. Hunter J. Laparoscopic transcystic common bile duct exploration. Am J Surg 1992;163(1):53-58. DOI: 10.1016/0002-9610(92)90252-m.

17. Carroll BJ, Phillips EH, Daykhovsky L, et al. Laparoscopic choledochoscopy: an effective approach to the common duct. J Laparoendosc Surg 1992;2(1):15-21. DOI: 10.1089/lps.1992.2.15.

18. Sackier JM, Berci G, Pas-Partlow M. Laparoscopic transcysticcholedochotomy as an adjunct to laparoscopic cholecystectomy. Am Surg 1991;57(5):323-326. PMID: 1828133.

19. Jacobs M, VCerdeja JC, Goldstein HS. Laparoscopic choledocholithotomy. Jnl Laparoendosc Surg 1991;1(2):79-82. DOI: 10.1089/ Ips.1991.1.79.

20. Quattlebaum JK, Flanders HD. Laparoscopic treatment of common bile duct stones. Surg Laparosc Endosc 1991;1(1):26-32. PMID: 1669373.

21. Appel S, Krebs H, Fern D. Techniques for laparoscopic cholangiography and removal of common duct stones. Surg Endosc 1992;6(3):134-137. DOI: 10.1007/BF02309086.

22. Vezakis A, Fragulidis G, Polydorou A. Endoscopic retrograde cholangiopancreatography-related perforations: diagnosis and management. World J Gastrointest Endosc 2015;7(14):1135-1141. DOI: 10.4253/wjge.v7.i14.1135.

23. Fanning NF, Horgan PG, Keane FBV. Evolving management of common bile duct stones in the laparoscopic era. J R Coll Surg Edinb 1997;42(6):389-394. PMID: 9448394.

24. Heili MJ, Wintz NK, Fowler DL. Choledocholithiasis: endoscopic versus laparoscopic management. Am Surg 1999;65(2):135-138.
25. Baloyiannis I, Tzovaras G. Current status of laparoendoscopic rendezvous in the treatment of cholelithiasis with concomitant choledocholithiasis. World J Gastrointest Endosc 2015;7(7):714-719. DOI: 10.4253/wjge.v7.i7.714.

26. Hamouda AH, Goh W, Mahmud S, et al. Intraoperative cholangiography facilitates simple transcystic clearance of ductal stones in units without expertise for laparoscopic bile duct surgery. Surg Endosc 2007;21(6):955-959. DOI: 10.1007/s00464-006-9127-2.

27. Mourad FH, Khalifeh M, Khoury G, et al. Common bile duct obstruction secondary to a balloon separated from a Fogarty vascular embolectomy catheter during laparoscopic cholecystectomy. Surg Endosc 2000;14(5):500-501. DOI: 10.1007/s004640000128.

28. Ahmed T, Alam MT, Ahmed SU, et al. Role of intraoperative flexible Choledochoscopy in calculous biliary tract disease. Mymensingh Med J 2012;21(3):462-468. PMID: 22828544.

29. Darwin P, Goldberg E, Uradomo L. Jackson Pratt drain fluidto-serum bilirubin concentration ratio for the diagnosis of bile leaks. Gastrointest Endosc 2010;71(1):99-104. DOI: 10.1016/j. gie.2009.08.015.

30. Conrad C, Wakabayashi G, Asbun HJ, et al. IRCAD recommendation on safe laparoscopic cholecystectomy. J Hepatobiliary Pancreat Sci 2017;24(11):603-615. DOI: 10.1002/jhbp.491.

31. Koch M, Garden OJ, Padbury R, et al. Bile leakage after hepatobiliary and pancreatic surgery: a definition and grading of severity by the International Study Group of Liver Surgery.Surgery 2011;149(5):680688. DOI: 10.1016/j.surg.2010.12.002.

32. Scientific Committee of the European Association for Endoscopic Surgery (E.A.E.S.). Diagnosis and treatment of common bile duct stones (CBDS). Results of a consensus development conference. Surg Endosc 1998;12(6):856-864. PMID: 9602006.

33. Bray MS, Borgert AJ, Folkers ME, et al. Outcome and management of endoscopic retrograde cholangiopancreatography perforations: a community perspective. Am J Surg 2017;214(1):69-73. DOI: 10.1016/j. amjsurg.2017.01.034.

34. Koc B, Karahan S, Adas G, et al. Comparison of laparoscopic common bile duct exploration and endoscopic retrograde cholangiopancreatography plus laparoscopic cholecystectomy for choledocholithiasis: a prospective randomized study. Am J Surg 2013;206(4):457-463. DOI: 10.1016/j.amjsurg.2013.02.004.

35. Rogers SJ, Cello JP, Horn JK, et al. Prospective randomized trial of $\mathrm{LC}+\mathrm{LCBDE}$ vs ERCP/S+LC for common bile duct stone disease. Arch Surg 2010;145(1):28-33. DOI: 10.1001/archsurg.2009.226.

36. Bansal VK, Misra MC, Rajan K, et al. Single-stage laparoscopic common bile duct exploration and cholecystectomy versus twostage endoscopic stone extraction followed by laparoscopic cholecystectomy for patients with concomitant gallbladder stones and common bile duct stones: a randomized controlled trial. Surg Endosc 2014;28(3):875-885. DOI: 10.1007/s00464-013-3237-4.

37. Del Pozo D, Tabernero S, Poves E, et al. Usefulness of endoscopic ultrasonography in the clinical suspicion of biliary disease. Rev Esp Enferm Dig 2011;103(7):345-348. DOI: 10.4321/s113001082011000700002.

38. Pérez-Cuadrado E. El papel de la ecoendoscopia en la vía biliar. La gran amiga de la ERCP. Rev Esp Enferm Dig 2011;103(7):341-344. DOI: 10.4321/S1130-01082011000700001.

39. Podda M, Polignano1 FM, Luhmann A, et al. Systematic review with meta-analysis of studies comparing primary duct closure and T-tube drainage after laparoscopic common bile duct exploration for choledocholithiasis. Surg Endosc 2016;30(3):845-861. DOI: 10.1007/ s00464-015-4303-x.

40. Phillips EH, Liberman M, Carroll BJ, et al. Bile duct stones in the laparoscopic era. Is preoperative sphincterotomy necessary? Arch Surg 1995;130(8):880-886. DOI: 10.1001/ archsurg.1995.01430080082013.

41. Hoyuela C, Cugat E, Bretcha P, et al. Must CPRE be routinely performed if choledocholithiasis is suspected? Dis Surg 1999;16(5):411-414. DOI: 10.1159/000018757. 
42. Sgourakis G, Lanitis S, Karaliotas Ch, Gockel I, Kaths M, Karaliotas C. Laparoscopic versus endoscopic primary management of choledocholithiasis. A retrospective case-control study. Chirurg. 2012 Oct;83(10):897-903. DOI: 10.1007/s00104-012-2279-9. https:// pubmed.ncbi.nlm.nih.gov/22476872/.

43. Freeman ML, Nelson DB, Sherman S, et al. Complications of endoscopic biliary sphincterotomy. N Engl J Med 1996;335(13): 909-918. DOI: 10.1056/NEJM199609263351301.

44. Loperfido S, Angelini G, Benedetti G, et al. Major early complications from diagnostic and therapeutic ERCP: a prospective multicenter study. Gastrointest Endosc 1998;48(1):1-10. DOI: 10.1016/s00165107(98)70121-x.

45. Masci E, Toti G, Mariani A, et al. Complications of diagnostic and therapeutic ERCP: a prospective multicenter study. Am J Gastroenterol 2001;96(2):417-423. DOI: 10.1111/j.1572-0241.2001.03594.x.

46. Rituerto C. Complications in biliary surgery. Cir Esp 2001;69:261-268.

47. Scollay JM, Mullen R, McPhillips G, et al. Mortality associated with the treatment of gallstone disease: a 10 year contemporani national experience. World J Surg 2011;35:643-647. DOI: https://doi. org/10.1007/s00268-010-0908-3 \t_blank 10.1007/s00268-010-0908-3. 